\title{
A COMPREENSÃO DA REALIDADE SOCIAL E A ESPECIFICIDADE DO “OBJETO” DA SOCIOLOGIA NA ANÁLISE WEBERIANA
}

\section{Suely Aparecida Martins}

Pós-graduanda, nível de mestrado, pela Universidade Estadual de Campinas.

\begin{abstract}
Tendo como parâmetro principal a compreensão de Max Weber sobre a realidade social, este artigo pretende apresentar algumas questões fundamentais da metodologia deste autor, essencialmente no que se refere ao objeto de estudo da sociologia, de modo a ressaltar como Weber entendeu a relação sujeito-objeto e a relação conceito-realidade no processo de conhecimento científico.
\end{abstract}

Palavras-chave: Sociologia compreensiva; tipo-ideal.

\section{INTRODUÇÃO}

$\mathbf{E}$ ste artigo tem como objetivo central apresentar algumas questões fundamentais quanto à metodologia weberiana, principalmente no que se refere ao objeto de estudo da sociologia.

Serão enfatizadas algumas das concepções de Weber sobre a realidade social, a relação sujeito-objeto e a relação conceito-realidade, de modo a ressaltar que a compreensão deste autor sobre a realidade é fundamental na construção de sua abordagem teórica.

A realidade para Weber, sendo infinita e inesgotável, perpassada por valores e caracterizada pela diversidade, jamais pode ser apreendida em sua totalidade. $O$ conhecimento científico, assim, não traduz a reprodução integral do real, mas é apenas um conhecimento parcial e provisório. Do mesmo modo, torna-se impossível na ciência social um método científico que seja definitivo. Dessa maneira, "só há ciência do que existe. O problema vem a ser, portanto, explicar o que existe, enveredando de modo geral pelo caminho da pesquisa das causas". (FREUND, 1987, p. 39) E o existente numa pesquisa científica é decidido com base nas perguntas que o pesquisador formula à realidade e estas só tem vida quando relacionadas à valores.

Num primeiro momento será dado destaque ao enfoque weberiano sobre o objeto de estudo da sociologia, com seu caráter subjetivo, permeado por valores tanto na forma como se apresenta ao cie ntista, como também servindo de critério para que este delimite a parte do real que deseja investigar. Depois, além de tratar da questão da objeti- vidade científica, será apresentado o conceito de tipo ideal que traduz um esforço deste autor para romper com o cientificismo e com o empiricismo.

Cabe ressaltar que sempre é frutífero um retorno aos clássicos da sociologia, principalmente num momento em que a discussão sobre a objetividade/subjetividade no conhecimento científico tem voltado à tona, inclusive através das ciências físicas. ${ }^{1}$

\section{A REALIDADE NO PONTO DE VISTA WEBERIANO E O OBJETO DE ESTUDO DA SOCIOLOGIA}

\begin{abstract}
"Sociologia (no sentido aqui entendido desta palavra empregada com tantos significados diversos) significa: uma ciência que pretende compreender interpretativamente a ação social e assim explicá-la casualmente em seu curso e em seus efeitos. Por ação entende-se, neste caso, um comportamento humano (tanto faz tratar de um fazer externo ou interno, de omitir ou permitir) sempre que e na medida em que o agente ou os agentes o relacionem com um sentido subjetivo. Ação social, por sua vez, significa uma ação que, quanto a seu sentido visado pelo agente ou os agentes, se refere ao comportamento de outros, orientando-se por este em seu curso". (WEBER, M. Economia e Sociedade. Brasília: UNB, 1991, p. 03)
\end{abstract}


A questão metodológica na ciências sociais tem sido discutida sob diversas formas. No século XIX buscou-se o caráter científico destas ciências, através da garantia de sua objetividade. Para tanto era necessário que estas ciências seguissem os procedimentos metodológicos das ciências naturais, de forma que pudessem através da observação dos fatos sociais obter suas regularidades e com isso estabelecer as leis gerais do desenvolvimento das sociedades humanas. Tal empreendimento científico ficou a cargo da corrente que passou a ser conhecida como positivista, tendo em Auguste Comte e principalmente Émile Durkheim seus principais autores.

Tal método empregado nas ciências sociais pelos positivistas destacava a necessidade da rígida separação entre pesquisador e objeto de conhecimento, ou seja, era preciso que o pesquisador se mantivesse distante em relação ao objeto observado de modo que não deixasse que suas prenoções interferissem tanto na escolha como no processo e resultado da investigação. Em tal abordagem os fatos sociais são tratados como coisas, tendo portanto, uma realidade própria que independe dos indivíduos. ${ }^{2} \mathrm{O}$ pesquisador deve observar esta realidade a partir de suas regularidades. Neste caso, o próprio conhecimento científico constitui-se como a imagem do fato social observado, ou ainda, trata-se de sua representação teórica. Portanto, o conceito é tido como um reflexo da própria realidade social.

No início do século XX, embora o método positivista já houvesse conquistado sua hegemonia, passou a ser questionado principalmente na Alemanha, através da corrente que se denominou anti-positivista e que reivindicava a autonomia das ciências humanas frente às ciências naturais. ${ }^{3}$ Esta corrente encontrou em Dilthey e $\mathrm{H}$. Richert seus principais representantes. Dilthey, por exemplo, postulava que as ciências humanas eram diferentes das ciências naturais, uma vez que lidavam com fenômenos de outra natureza: fenômenos que passavam pelos indivíduos nunca como entidade isola$\mathrm{da}$, pois "ele se constitui intersubjetivamente, sua natureza é social e, sobretudo, cultural" (COHN, 1979, p. 18), sendo que deveriam ser compreendidos em suas relações de sentido. Por sua vez, Rickert viu na realidade algo infinito, impossível de ser compreendido em sua totalidade e no caso específico da realidade social enfatizou o caráter singular, único de cada fenômeno social.

A distinção estabelecida entre ciências humanas e ciências da natureza, feita por Dilthey, por exemplo, colocou várias interrogações acerca da objetividade nas ciências humanas, bem como em relação ao processo de conhecimento nesta ciência. Max Weber aprofundou tais questões e construiu uma metodologia própria para o que ele designava como ciências da cultura, sem, no entanto, abrir mão da busca da objetividade científica.

É, entre outros, no texto 'A 'objetividade' do conhecimento nas Ciências Sociais", publicado pela primeira vez em 1904, e que servirá de base para este artigo, que pode-se encontrar algumas questões metodológicas básicas norteadoras do pensamento de Weber, bem como perceber o seu diálogo com o marxismo. ${ }^{4}$ Weber inscreve-se também no grupo dos críticos do positivismo, especialmente no que se refere à proximidade desta corrente às ciências naturais e a seu método.
Tais questões indicam que para Weber não há uma cisão entre ciência e valores. Conforme ARON, "a ciência weberiana se define (...) como um esforço destinado a compreender e a explicar os valores aos quais os homens aderiram, e as obras que construíram" (1987, p.470). Pode-se, assim, dizer que para Weber tanto a realidade como a busca de sua compreensão através da ciência é transpassada por valores; valores estes que se encontram impregnados nas ações dos sujeitos. Para Weber faz-se necessário captar a relação de sentido da ação humana, cabe, portanto, ao sociólogo "descobrir o sentido subjetivo das ações". (FERNANDES, 1967, p. 88).

Percebe-se, assim, que a realidade social, que interessa ao estudo da sociologia, não é compreendida em termos estritamente objetivos e concretos e com natureza diferente da dos agentes individuais. Pelo contrário, para Weber somente é possível compreender um fenômeno social a partir de agentes individuais, pois são estes que conferem sentido às suas ações e que podem comportar uma multiplicidade de significados simultaneamente. Conforme $\mathrm{COHN}$, cabe ao sociólogo a tarefa de compreender o sentido da ação do sujeito, buscando apreender o motivo que sustenta esta ação. Reconstruir este "motivo" é essencial, pois ele configura-se como a causa da ação, apontando para o objetivo visado nela. No entanto, a ação social não deve ser compreendida como um ato isolado, mas como "um processo, no qual se percorre uma seqüência definida de elos significativos". (COHN, 1991, p. 27) Para compreender o sentido da ação é necessário, portanto, "apreender os nexos entre os diversos elos significativos de um processo particular de ação e reconstruir esse processo como uma unidade que não se desfaz numa poeira de atos isolados". (COHN, 1991, p.28)

E Weber considera que a realidade social, fundada a partir dos agentes individuais, encontra-se imbuída de elementos subjetivos e mais precisamente de elementos culturais. E segundo o próprio Weber: "O conceito de cultura é um conceito de valor. A realidade empírica é 'cultura' para nós porque e na medida em que a relacionamos a idéias de valor". (WEBER, 1991, p. 92) E será possível apreender tal realidade em sua totalidade? Weber responde que não, uma vez que esta é infinita, diversificada, inesgotável e apresenta múltiplas significações.

Desta concepção de realidade deriva-se questões significativas:

1. A realidade só pode ser apreendida de forma parcial e limitada:

"Assim, todo conhecimento reflexivo da realidade infinita realizado pelo espírito humano finito baseiase na premissa tácita de que apenas um fragmento dessa realidade poderá constituir de cada vez o objeto de compreensão científica" (WEBER, 1991, p.88);

2. Não existe nas ciências da cultura um conhecimento fechado e unilateral sobre a realidade, ou seja, as significações culturais de um objeto a ser analisado são muitas, o que invalida a pretensão de explicar a realidade a partir de 
um único fator causal determinante. Neste aspecto alerta Weber, criticando o determinismo econômico: "Em nenhum dos fenômenos culturais pode a redução unicamente a causas econômicas ser exaustiva, mesmo no caso específico dos fenômenos econômicos" (WEBER, 1992, p.86);

3. Sendo a realidade infinita e inesgotável, "Weber nega que o conhecimento possa ser uma reprodução ou uma cópia integral da realidade, tanto no sentido de extensão, como da compreensão" (FREUND, 1987, p. 33), quer dizer que, o conhecimento científico da realidade não pode ser confundido com a própria realidade, uma vez que é este apenas uma das formas possíveis (ainda que baseada na racionalidade) de conhecer uma parte ínfima da realidade infinita.

\section{A OBJETIVIDADE NA RELAÇÃO ENTRE O CIENTISTA E O OBJETO DE PESQUISA}

Postas estas questões faz-se necessário voltar a falar sobre os valores nas ciências sociais. Como já colocado anteriormente a própria realidade empírica para Weber é permeada por valores, além de ser uma realidade inesgotável e infinita. Frente a tal realidade, o que define a partícula do real a ser estudada, constituindo-se como objeto de pesquisa? E o que garante a objetividade científica perante uma realidade que tem "obras carregadas de valores"? (ARON, 1987, p.470)

Aqui é importante enfatizar a relação entre sujeito e objeto no processo de construção do conhecimento científico para Weber. Esta relação é possível justamente porque cabe ao sujeito-investigador selecionar, a partir de seus valores, o objeto a ser estudado. Sendo assim, o objeto de estudo científico não encontra-se dado a priori na realidade social, uma vez que o recorte que delimita o objeto a ser estudado está, conforme Weber, "condicionado pela orientação do nosso interesse de conhecimento, e essa orientação define-se conforme o significado cultural que atribuímos ao evento em questão em cada caso particular" (WEBER, 1991, p. 79)

Portanto, o processo de conhecimento inicia-se na própria opção do sujeito-investigador, que através de seus valores, define se quer analisar, por exemplo, um fenômeno social pela sua importância religiosa ou econômica. Tal decisão está condicionada pelos interesses valorativos do sujeito-investigador. Neste aspecto, entende-se porque Weber diz que o "caráter de um evento não é algo que lhe seja 'objetivamente' inerente. (1992, p. 79). Novamente esta questão relaciona-se ao fato de Weber perceber a realidade como sendo algo infinito, inesgotável e recortada por valores, o que permite que num mesmo fenômeno social encontrem-se elementos diversificados, que somente através do interesse do pesquisador, podem ser explorados em suas singularidades. Assim, a pesquisa não esgota a realidade a ser estudada, antes aponta um tipo de "olhar" sobre esta realidade social. Tal questão torna-se crucial no pensamento de Weber, pois o caracteriza como contrário a qualquer tipo de determinismo social, em outros termos: é impossível nas ciências sociais a redução da realidade social a um único elemento desta realidade. Fica evidente assim, a crítica de Weber ao materialismo histórico. E segundo GERTH e MILLS:

"[Weber] sentia que Marx, como economista, havia cometido o mesmo erro que, durante a época de Weber a Antropologia estava cometendo: dando a uma perspectiva parcial uma importância exagerada e reduzindo a multiplicidade de fatores causais a um teorema de fator único". (1968, p. 315)

Para Julien FREUND tal abordagem se afasta da síntese romântica e doutrinária de Comte, Marx ou Spencer, assumindo uma "análise modesta, precisa e prudente". Continua FREUND:

"O que nos parece essencial aqui, é que todos [Comte, Spencer e Marx] partiam de uma idéia da sociedade, da cultura ou da civilização entendidas como um todo (...)pressupunham (...) uma unidade a priori da história passada e futura, de maneira que não haveria nenhuma dificuldade de ler o pretenso sentido único e global do futuro" (1987, p.13).

Para Weber tal pretensão era impossível pela inesgotável riqueza do real que jamais poderia ser apreendido de forma total e absoluta.

Uma outra questão pertinente sobre isso refere-se a própria finalidade da ciência para Weber, que se diferencia desses autores, pois não se trata de uma ciência normativa. Weber considera que não caberia ao conhecimento científico indicar aos homens o caminho a seguir. Ou ainda não seria tarefa da ciência responder a questão: "Que deus devemos servir dentre os muitos que se combatem? Devemos, talvez, servir um outro deus, mas qual?" (WEBER, 1968, p. 48). A ciência deveria servir para demonstrar os diversos caminhos que estariam sendo seguidos e suas consequiências, porém jamais poderia indicá-lo:
"Os cientistas podem - e devem - mostrar que tal ou qual posição adotada deriva, logicamente e com toda certeza, quanto ao significado de tal ou qual vi- são última e básica do mundo. Uma tomada de posi- ção pode derivar de uma visão única do mundo ou de várias diferentes entre si. Dessa forma, o cientista pode esclarecer que determinada posição deriva de uma e não de outra concepção (...) A ciência mostrará que, adotando tal posição, certa pessoa estará a serviço de tal Deus e defendendo tal outro e que, se se desejar manter fiel a si mesma, chegará, certamente, a deter- minadas conseqüências íntimas, últimas e significati- vas. Eis o que a ciência pode proporcionar, ao menos em princípio". (WEBER, 1968, p. 46)

Novamente é importante dar ênfase ao fato de que para Weber não há um único conhecimento científico possível, ele é um entre as diversas formas de apreender o real, que está orientado pelo compromisso em aproximar-se da 
verdade. E é este valor que define a vocação científica, ou seja, acreditar "que o resultado a que o trabalho científico leva é importante em si, isto é, merece ser conhecido" (WEBER, 1968, p. 36). Portanto, é por acreditar na validade da ciência e na sua importância como conhecimento parcial da realidade que Weber acredita na objetividade desta ciência. Mas, como isso é possível se o próprio objeto de estudo depende dos interesses do sujeito-investigador e se a própria realidade encontra-se impregnada pela subjetividade?

Conforme ARON (1987, p.470) a objetividade do conhecimento científico é garantida através da distinção feita por Weber entre o julgamento de valor (caracterizados por serem pessoais e subjetivos e que definem o objeto de pesquisa a ser estudado pelo sujeito-investigador) e a relação com os valores que definem-se como "um procedimento de seleção e de organização da ciência objetiva". Enquanto o julgamento de valor refere-se a um ponto de vista particular e que, portanto, revela o apreço ou não do sujeito a determinada questão, a relação com valores quer dizer que "o cientista relaciona a matéria estudada com um valor", independente do fato de aprová-lo ou não.

Este procedimento metodológico torna-se possível através de um esforço intelectual do sujeito-investigador que, ao assumir sua "vocação científica" deixa de lado suas convicções políticas e religiosas, por exemplo, substituindo-as pela crença no conhecimento científico, uma vez que "o ato científico, enquanto conduta racional, se orienta pelo valor da verdade universalmente válida (ARON, 1987, p.474), portanto, cabe ao sujeito-investigador aderir aos procedimentos científicos considerados válidos em sua época:

“(...) No que se refere ao método da investigaçãoo 'como' - é o ponto de vista dominante que determina a formação dos conceitos auxiliares de que se utiliza; e quanto ao modo de utilizá-los o investiga. dor encontra-se evidentemente ligado às normas de nosso pensamento. Porque só é uma verdade científica aquilo que pretende ser válido para todos que querem a verdade". (WEBER, 1991, p. 100)

Weber, postula assim, que qualquer conhecimento que se pretenda científico deve ter seus resultados reconhecidos como válidos por todos aqueles que querem a verdade: " $\mathrm{Com}$ efeito, é verdade e continua a sê-lo que na esfera das ciências sociais uma demonstração científica, metodicamente correta, que pretende ter atingido seu fim, deve poder ser reconhecida como exata igualmente por um chinês". (apud FREUND, 1987, p. 64)

Embora, Weber considere que o objetivo da ciência é a busca da verdade isso não significa que se trate de uma verdade definitiva e insuperável, pois "a verdade sempre deixa uma margem de sombras, que não esgota a realidade do passado, e menos ainda do futuro" (apud HIRANO, p. 15). E segundo Freund, tratando-se para Weber de uma realidade que é infinita isso implica que o próprio conhecimento tem seus limites na dinâmica do real e do saber, uma vez que "o conhecimento e a ação nunca se realizam definitivamente, pois todo o conhecimento requer outros conhecimentos, e toda ação, outras ações". (FREUND, 1987, p.12)
A infinitude do real permite sempre novas interrogações sob outros pontos de vista. Isso quer dizer que nenhum conhecimento esgota a diversidade do real, nem consegue ser seu sinônimo:

"Nenhuma ciência particular, nem tampouco o conjunto das ciências, tem condições para satisfazer nosso saber, porque o entendimento não é capaz de reproduzir ou copiar o real, mas unicamente de elaborá-lo por força dos conceitos (...) Até o nosso saber adquirido, seja ele o mais sólido aparentemente, se deixa questionar quando um sábio o encara de um ponto de vista novo e inédito". (FREUND, 1987, p.12)

Dessa maneira, cabe perguntar acerca do papel dos conceitos no processo de conhecimento científico e como estes se relacionam com a realidade a ser analisada.

\section{A ORDENAÇÃO DO REAL PELO PENSAMENTO: O CONCEITO DE TIPO-IDEAL}

Primeiramente é preciso ter claro que para Weber a realidade vista pelo cientista não se apresenta a ele de maneira racional, antes expõe fenômenos sociais fragmentados e desarticulados entre si, principalmente "quando as relações causais dadas são incontáveis e quando simultaneamente cada elemento desta realidade se encontra num relacionamento diversificado com outros elementos (...)" (KOCKA, 1997, p.40), surgindo aos olhos do observador como caótica. Para Weber

"Este caos só pode ser ordenado pela circunstância de que, em qualquer caso, unicamente um segmento da realidade individual possui interesse e significado para nós, posto que só ele se encontra em relação com as idéias de valor culturais com que abordamos a realidade". (WEBER, 1991, p. 94)

É através da formulação de conceitos que conseguese chegar a uma ordenação do real, visando a sua compreensão, portanto, "os conceitos sociológicos (...) devem ser manipulados como conceitos destinados a servir como instrumentos científicos na ordenação sociológica da realidade". (FERNANDES, 1968, p. 94) Os conceitos são assim utilizados como meios heurísticos na compreensão do real, não se confundindo com o real. Trata-se de uma abstração do pensamento que permite proceder à uma análise comparativa entre o ideal (o que encontra-se ordenado racionalmente pelo pensamento) e o real (o fenômeno observado contendo elementos racionais e irracionais). Assim, chegamos aquilo que Weber definiu como tipo ideal que, segundo este autor, é formado pela exageração de um ou mais traços, ou pontos de vista, observáveis na realidade social.

Para Weber o tipo ideal não é encontrado nunca em estado puro na realidade dos fenômenos observados, pois

Rev. Mediações, Londrina, v. 3, n. 2, p. 41-46, jul./dez. 1998 
trata-se de uma construção mental que não deve ser confundida com o fenômeno social a ser estudado. O tipo ideal deve ser utilizado como "um instrumento de orientação da realidade empírica e meio para a elaboração de hipóteses". (COHN, 1991, p. 29) Ainda é plausível salientar, conforme Florestan Fernandes, que os conceitos, entendidos como tipos ideais, são gerais e unívocos, e por serem utilizados como meio heurístico "parecem relativamente vazios diante da realidade histórica". (FERNANDES, 1968, p. 92)

Como já colocado anteriormente, o objeto de estudo que interessa à sociologia constitui-se na captação do sentido da ação social na sua multiplicidade, ou seja, interessa à sociologia compreender a relação social, entender como diversos agentes individuais se orientam por um conteúdo de sentido reciprocamente compartilhado. A relação social figura-se assim, como um desdobramento da ação social que comporta certas regularidades e tem caráter coletivo, ${ }^{5}$ e frente a uma realidade infinita que incorpora a diversidade de seus agentes e o sentido de suas ações como "feixes inesgotavelmente diversificados de processos que se mesclam de todas as maneiras" (COHN, 1991, p. 29) é impossível a análise científica querer apreender a realidade da forma como esta se apresenta empiricamente. Assim, os tipos ideais servem como instrumentos que permitem um ordenamento racional de parte desta realidade, e que após construídos no plano do pensamento podem ser comparados com o real. Mas como se constrói o tipo ideal?

\begin{abstract}
"Obtém-se um tipo ideal mediante a acentuação de um ou vários pontos de vista, e mediante o encadeamento de grande quantidade de fenômenos isoladamente dados (...) e que se ordenam segundo os pontos de vista unilateralmente acentuados, a fim de se formar um quadro homogêneo de pensamento. Torna-se impossível encontrar empiricamente na realidade esse quadro, na sua pureza conceitual, pois trata-se de uma utopia". (WEBER, 1991, p.106)
\end{abstract}

Portanto, esses tipos são construídos no pensamento do pesquisador e não nos próprios fenômenos. Vale a pena aqui a opinião do historiador marxista E.P. Thompson sobre a forma como os fatos históricos se apresentam ao pesquisador, revelando a importância da teoria, sem, no entanto, abrir mão de seu diálogo com a realidade empírica: "Os fatos estão ali, inscritos no registro histórico, mas isso não implica, de certo, uma noção de que esses fatos revelam seus significados e relações (conhecimento histórico) por si mesmos, e independentemente dos procedimentos teóricos". (THOMPSON, 1981, p. 37)

Tal diálogo também é importante para Weber, uma vez que embora os tipos ideais sejam obtidos através do pensamento, isso não quer dizer que sejam concebidos de forma autônoma em relação a realidade, sendo obras exclusivas do pensamento:

"O tipo ideal não é elaborado pelo pensamento puramente conceitual, mas antes criado, modificado $e$ aperfeiçoado através da análise empírica de problemas concretos, contribuindo por seu turno para que essa análise adquira uma maior precisão". (GIDDENS, 1972, p. 236)

Assim, o tipo ideal visa a enfatizar determinados traços da realidade para poder concebê-la na sua expressão mais pura e por isso jamais existente na realidade histórica concreta, e segundo Weber, "tem antes o significado de um conceito limite puramente ideal, em relação ao qual se mede a realidade a fim de esclarecer o conteúdo empírico de alguns de seus elementos importantes, e com o qual esta é comparada". (WEBER, 1991, p. 109)

Weber ainda adverte para não confundir o tipo ideal com o que "deve ser" ou "o exemplar". O tipo ideal deve apenas ser utilizado como um recurso metodológico que permite ao investigador reter o que é essencial em uma determinada configuração histórica particular, mostrando, assim, sua originalidade e servindo como parâmetro de comparação com outras configurações históricas. Como exemplo, destaca Freund o tipo ideal do capitalismo:

"O tipo ideal do capitalismo reúne (...) em um quadro de pensamento, os traços característicos que definem sua originalidade de doutrina econômica, mesmo que só se encontrem de modo difuso na realidade, e mesmo que outro esteja ausente de uma organização econômica completa. O tipo ideal do capitalismo compreende igualmente as tendências e os fins a que ele visa como objetivo, mesmo que não tenha sido realizados plenamente em parte alguma". (FREUND, 1987, p. 50)

Desse modo, o sociólogo munido do tipo ideal do capitalismo pode usá-lo enquanto meio heurístico para compreender o capitalismo seja na América do Norte ou na Europa. Neste aspecto o conceito de capitalismo serve para ajudar a entender determinada configuração histórica particular, no entanto, não serve como substancialização desta realidade, uma vez que os conceitos " $n \tilde{a} o$ são cópias representativas da realidade "objetiva" (WEBER, 1991, p. 122) ${ }^{6}$ Assim, para Weber os conceitos apenas servem para proceder a uma comparação entre estes e a realidade, ajudando o investigador a compreender, de forma parcial, determinada realidade em suas singularidades.

\section{CONCLUSÃO}

A partir das questões aqui colocadas, pode-se concluir que em Weber existe um esforço para romper tanto com o cientificismo (dedução do real a partir de conceitos teóricos), como também com o empiricismo (apreensão do real apenas por observações empíricas e sem a necessidade de construções teóricas).

Em Weber tal esforço é resultado de uma metodologia que:

1.percebe a realidade como sendo infinita e inesgotável, portanto, impossível de ser apreendida em sua totalidade. Neste 
aspecto, todo conhecimento é sempre um conhecimento parcial da realidade;

2.busca entender a realidade social através da compreensão do sentido das ações dos sujeitos, sendo assim, uma realidade impregnada pela subjetividade e por valores culturais. E são os valores do sujeito investigador que determinam a partícula do real a ser estudada;

3.vê ainda que esta realidade não se apresenta ao sujeito investigador de forma organizada e racional, antes parece caótica. É através da abstração pelo pensamento que o pesquisador ordena de forma racional esta realidade, procedendo à construção dos tipos ideais;

4.concebe o tipo-ideal como uma construção do pensamento, que não se confunde jamais com a realidade, embora dependa dela para ser elaborado. Assim, o tipo ideal é resultado do diálogo entre o empírico e o teórico;

5.acredita na possibilidade da objetividade científica na sociologia, mesmo que o seu objeto de estudo seja recortado a partir dos valores do sujeito pesquisador. E essa própria objetividade é garantida por um valor, ou seja, a busca da verdade científica, que faz com que o pesquisador no processo de conhecimento abdique de outros valores em nome da ciência. Para tanto, deve aderir aos métodos e rigores científicos de sua época e construir um conhecimento que seja reconhecido como válido universalmente;

6.entende a ciência como um conhecimento racional da realidade social (que nunca se confunde com a própria realidade), porém, não é o único conhecimento possível do real, e não cabe à ciência indicar aos homens qual o melhor caminho a seguir, apenas mostrar os diversos caminhos seguidos e suas consequiências. A escolha depende exclusivamente dos sujeitos, podendo estar embasada na razão e na fé. $E$ isso não cabe à ciência resolver.

Assim, pode-se perceber que a perspectiva da abordagem weberiana é possível devido a sua própria concepção sobre a realidade, o que inclui elementos subjetivos, tratando-se de uma realidade cultural. Ao perceber a realidade como algo infinito e inesgotável, Weber vê o próprio limite do conhecimento científico que ao esbarrar na infinitude do real e nos valores dos sujeitos, jamais consegue ser um conhecimento total e absoluto do real, como também não se trata de um conhecimento que se confunda com tal realidade pesquisada. Portanto, nem o investigador e todo o trabalho científico pode dar conta deste feixe de sentidos da realidade humana, que é dinâmico e diversificado. Deste modo, o conhecimento científico do real é sempre um conhecimento parcial e provisório, que sempre pode ser superado.

\section{NOTAS}

' Sobre este aspecto ver: GLEISER, Marcelo. A dança do universo. São Paulo: Companhia das Letras, 1997 e SANTOS, Boaventura de Sousa. Um discurso sobre as ciências. Coimbra: Afrontamento, 1993.

2 A partir da física quântica esta questão tem sido questionada, inclusive pelos físicos: "A noção de que uma realidade objetiva existe independentemente da presença de um observador, parte fundamental da descrição clássica da Natureza, tem de ser abandonada. De certo modo, a realidade física observada (...), ao menos dentro do mundo do muito pequeno, é resultado de nossa escolha". (GLEISER, op. cit. p. 299)

3 Atualmente tal questão tem sido discutida de forma diferenciada por Boaventura de Sousa Santos (1993, op. cit.) que postulando uma nova ordem científica emergente acredita no fim da distinção entre ciências naturais e ciências sociais. Vislumbra a síntese entre estas ciências, tendo como polo catalizador as ciências sociais.

4 Vários autores, entre eles Giddens (1972), Gerth e Mills (1968) e Kocka (1997), consideram que Weber não dialoga diretamente com Marx, mas principalmente com a corrente marxista alemã de seu tempo.

$s$ É importante diferenciar a ação social da relação social: "na ação social a conduta do agente está orientada significativamente pela conduta de outro (outros)" - um aperto de mão, por exemplo; na relação social " $a$ conduta de cada qual entre múltiplos agentes envolvidos orienta-se por um conteudo de sentido reciprocamente compartilhado" - como exemplo, a amizade. (COHN, 1991, p. 30)

6 Sobre este aspecto está uma das advertências de Weber a um certo tipo de marxismo que reduz a realidade à conceitos. Tal advertência também é compartilhada por alguns marxistas contemporâneos, como o historiador E. P. Thompson, que faz uma crítica ao estruturalismo althusseriano, acusando este por seu "imperialismo teórico", por fazer uso das categorias marxistas como verdades únicas, confundindo-as com a própria realidade. Assim como Weber, Thompson considera que os conceitos teóricos devem ser utilizados como meio-heurísticos para a compreensão do real: "Se introduzimos conceitos, os estamos introduzindo como "modelos' que nos ajudam a investigar e organizar esses fatos; mas devemos deixar claro que esses modelos existem em nossa cabeça e não na história". (THOMPSON, 1981, p. 44)

\section{REFERÊNCIAS BIBLIOGRÁFICAS}

ARON, Raymond. As etapas do pensamento sociológico. São Paulo: Martins Fontes/UnB, 1987, p. 461-554

COHN, Gabriel. Introdução In.: WEBER, Max (org. Gabriel Cohn) Weber: sociologia. São Paulo: Ática, 1991, p. 7-34 (Coleção Grandes Cientistas Sociais $n^{\circ} 13$ )

. Critica e resignação: fundamentos da sociologia de Max Weber. São Paulo: T. A. Queiroz, 1979.

COLLIOT-THÉLÈNE, Catherine. Max Weber e a história. São Paulo: Brasiliense, 1995, p. 11-38

FERNANDES, Florestan. Fundamentos empíricos da explicação sociológica. São Paulo: Companhia Editora Nacional, 1967, p. 84-95

FREUND, Julien. Sociologia de Max Weber. Rio de Janeiro: Forense-Universitária, 1987, p. 9-66

GERTH, H. H; MILLS, Wrigh. Introdução. In.: WEBER, Max. Ensaios de sociologia. Rio de Janeiro: Zahar, 1974, p. 15-96

GIDDENS, Anthony. Capitalismo e moderna teoria social. Lisboa: Editorial Presença/Martins Fontes, 1971, p. 203-267; 301-385.

HIRANO, Sedi. Castas, estamentos e classes sociais. São Paulo: AlfaÔmega, 1973, p. 13-22

KOKCA, Jurgen. Objeto, conceito e interesse In.: GERTZ, René E. (org.). Max Weber e Karl Marx. São Paulo: Hucitec, 1997, p. 32-69

LAZARTE, Rolando. Max Weber: ciência e valores. São Paulo: Cortez, 1996 (Coleção Questões de nossa época n. 53)

THOMPSON. E. P. A miséria da teoria. Rio de Janeiro: Zahar, 1981

WEBER, Max. A "objetividade" do conhecimento nas Ciências Sociais. In.: WEBER, Max (org. Gabriel Cohn). Max Weber: sociologia. São Paulo: Ática, 1991, p. 79-127. p. $17-52$
Ciência e política: duas vocações. São Paulo: Cultrix, 1968. 